\title{
SPECIFIC AND NONSPECIFIC ACTIVITIES OF THE VISUAL SYSTEM IN RABBITS
}

\author{
Keiichi Mimura, Kensuke Sato, Shigeyoshi Teramoto, \\ Kazuo Kitajima, Yasuhiro Tagawa, Noriyoshi \\ Hirota AND Haruo Kitajima \\ The Second Department of Physiology, Nagasaki University \\ School of Medicine, Nagasaki, Japan
}

\begin{abstract}
Although it has been shown that the rises in cortical activities by 3 and $5 / \mathrm{sec}$ flash stimulations verified in the frequency response of the visual cortex of unanesthetized rabbits (MIMURA and SATO, 1965) can be correlated with the excitability changes of $5 / \mathrm{sec}$ (BISHOP, 1933) or $4-5 / \mathrm{sec}$ (PEARLMAN, 1963) in the visual cortex of the rabbit, it was not ascertained whether these excitability changes originated from the cortex itself or from subcortical structures nor was it ascertained whether it was from the specific or the nonspecific system. The present study is an attempt to solve the above problems through observations on the pattern of response to repetitive flash stimulations in the specific and non-specific systems of the cortex and subcortical structures of anesthetized and unanesthetized rabbits.
\end{abstract}

\section{METHOD}

Ten anesthetized and eleven unanesthetized rabbits weighing about $3 \mathrm{~kg}$ were used. The anesthetized experiments were carried out under an intraperitoneal administration of sodium pentobarbital at a rate of $15 \mathrm{mg} / \mathrm{kg} / 2 \mathrm{hrs}$. The animal was mounted on the Johnson type stereotaxic instrument. Intubation to the trachea under ether anesthesia was done in unanesthetized experiments and the animal was immobilized after opening the skull by intraperitoneal administration of Flaxedil throughout the experiment, which necessitated artificial respiration with oxygen-mixed air.

Stainless steel electrodes of $0.5 \mathrm{~mm}$ and/or $80 \mu$ diameter, insulated except at the tip, were inserted stereotaxically into the brain according to the atlases of SAWYER et al. (1954), Monnier and Gangloff (1961) and Fifková and Murśala (1962). Surface records from the cortex were taken with $0.5 \mathrm{~mm}$ diameter silver ball tipped electrodes. ERGs were recorded by placing the same silver ball electrode on the cornea. All recordings were monopolarly taken in relation to a reference electrode on the neck muscle. The location of the electrodes were checked histologically by the KLÜVER-BARRERA staining techniques (1953) after each experiment.

The exposed cortical surface was covered with warm mineral oil. The temperature

Received for publication November 6, 1966.

三村珪一, 任藤謙助, 寺本成美, 北島和夫, 田川安浩, 広田典祥, 北島陽夫 
of the shielded room was maintained at $28-29^{\circ} \mathrm{C}$ and sometimes a rubber bag filled with hot water was placed beneath the abdomen to keep the animal in good condition. The pupils were dilated with a $0.5 \%$ solution of atropine.

Stimulation was delivered by a photic stimulator to both eyes. A flash of $6000^{\circ} \mathrm{K}$, $100 \mathrm{usec}$ duration and $1 \mathrm{watt} / \mathrm{sec}$ energy from a strobo-flash bulb (Mazda, FT 100), which had been placed $50 \mathrm{~cm}$ away from the eyes, was used. The flash was passed through a $10 \mathrm{~cm}$ diameter iris and was further diffused through a frosted glass plate and a white curtain. Subcortical structures were stimulated by rectangular waves of 4-6. Volts intensity and $0.1-0.5 \mathrm{msec}$ duration through bipolar depth electrodes (distance between electrodes $0.5 \mathrm{~mm}$ ).

Ink records in the anesthetized animals and magnetic records on $1 / 4$ inch tape monitoring ink records in the unanesthetized animals were obtained simultaneously through a 8-channel polygraph (RM-150, Nihon Kohden, Tokyo) and 8-channel data recorder (SPRA-48, Shiroyama Tsûshin, Tokyo), respectively. The average response time-contours to flash and electrical stimulations were computed by the simplified method of SATo et al. (1962) in anesthetized experiments. Though the stimulation was delivered for $30-60 \mathrm{sec}$, ten evoked responses from the tracings between $3-10 \mathrm{sec}$ after the onset of the repetitive stimulation were selected to average the relatively constant amplitude of the evoked potentials. In the unanesthetized experiments, magnetic records of the responses were summed up thirty times to eliminate irrelevant background fluctuations over an analysis time of $500 \mathrm{msec}$ through the Digital Computer for Data Processing. (ATAC-401, Nihon Kohden, Tokyo).

\section{RESULTS}

\section{PART I. EVIDENCES IN THE ANESTHETIZED RABBITS}

1. Repetitive flash stimulation. A part of the trancings during repetitive flash stimulation and the average responses are shown in FIG. 1 and 2. The average evoked response in each brain site was found to consist of two or three components, in which the first and second components were marked here. In the cortex, the initial surface positive wave (peak latency: 60-95 msec) and the following surface positive $(95-208 \mathrm{msec})$; in the lateral geniculate body (GL), the initial (peak latency: $52-86 \mathrm{msec}$ ) and the following upward deflections $(112-172 \mathrm{msec})$; in the midbrain reticular formation $(\mathrm{RF}, \mathrm{P}+9 \mathrm{~L}+2.5 \mathrm{H}-3$ in the atlas of SAWYER et al.), the initial (peak latency: $35-65 \mathrm{msec}$ ) and the following downward deflections (108-155 $\mathrm{msec}$ ); in the superior colliculus (CS), the initial (peak latency: 43-65 msec) and the following downward deflections (99$146 \mathrm{msec}$ ) were studied. The primary response or the corresponding response is equal to the above initial potential. In this paper, the initial and the following deflections in each site except $R F$ were assigned the name potentials $A, A^{\prime}, B$ and $B^{\prime}$ respectively, whereas $A, B, B^{\prime}$ and $B^{\prime \prime}$ in $R F$. An example of the amplitudes of these potentials in relation to the flash frequencies (the amplitudes-frequency diagrams) is presented in FIG. $1 Z$ and $2 Z$. Peak(s) appeared in the curves from almost all sites. In GL, peaks appeared at $2 \mathrm{f} / \mathrm{sec}$ in the $A$ and $B$ potentials, and at 2 and $5 \mathrm{f} / \mathrm{sec}$ in the $A^{\prime}$ potential. In $R F$, 
$X$

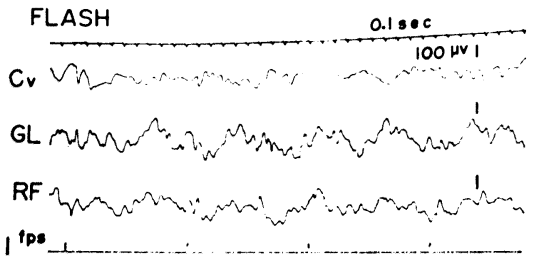

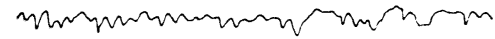

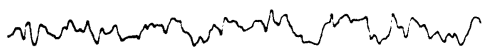

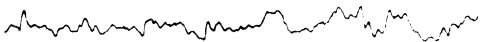

2

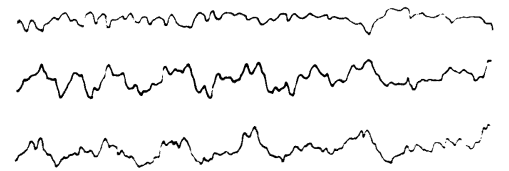

3

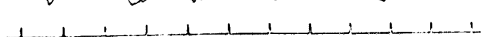

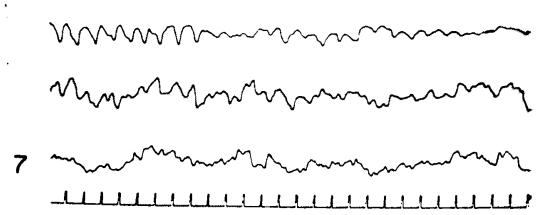

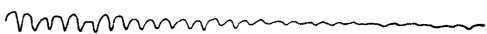

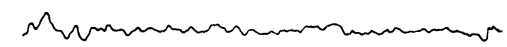

8

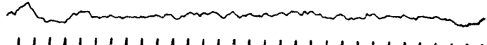

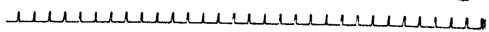
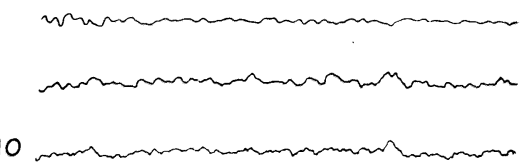

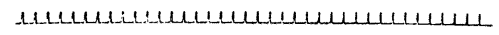
100-35

4
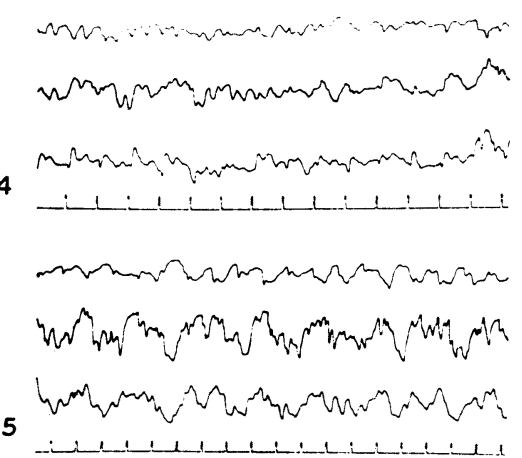

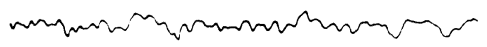

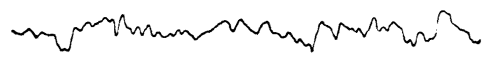

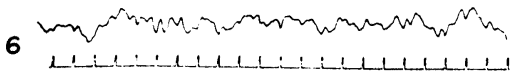

FIG. 1. Examples of the brain masspotential ink records $(X)$, the average response time-contours ( $Y$ ) and the amplitude-frequency diagrams $(Z)$. X: Ink records from the visual cortex $(\mathrm{Cv})$, lateral geniculate body (GL) and midbrain reticular formation (RF) during 1 to $10 / \mathrm{sec}$ flash stimulations. $\mathrm{Y}$ : Average response time-contours to various flash frequencies. $Z$ : Diagrams to depict the relation between the amplitude of each component (ordinate) and flash frequencies (abscissa). A, $A^{\prime}, B$ and $B^{\prime}$ or $B^{\prime \prime}: A, A^{\prime}, B$ and $B^{\prime}$ or $B^{\prime \prime}$ potentials respectively. Upward deflection in the time-patterns in all figures of this paper is negative. 

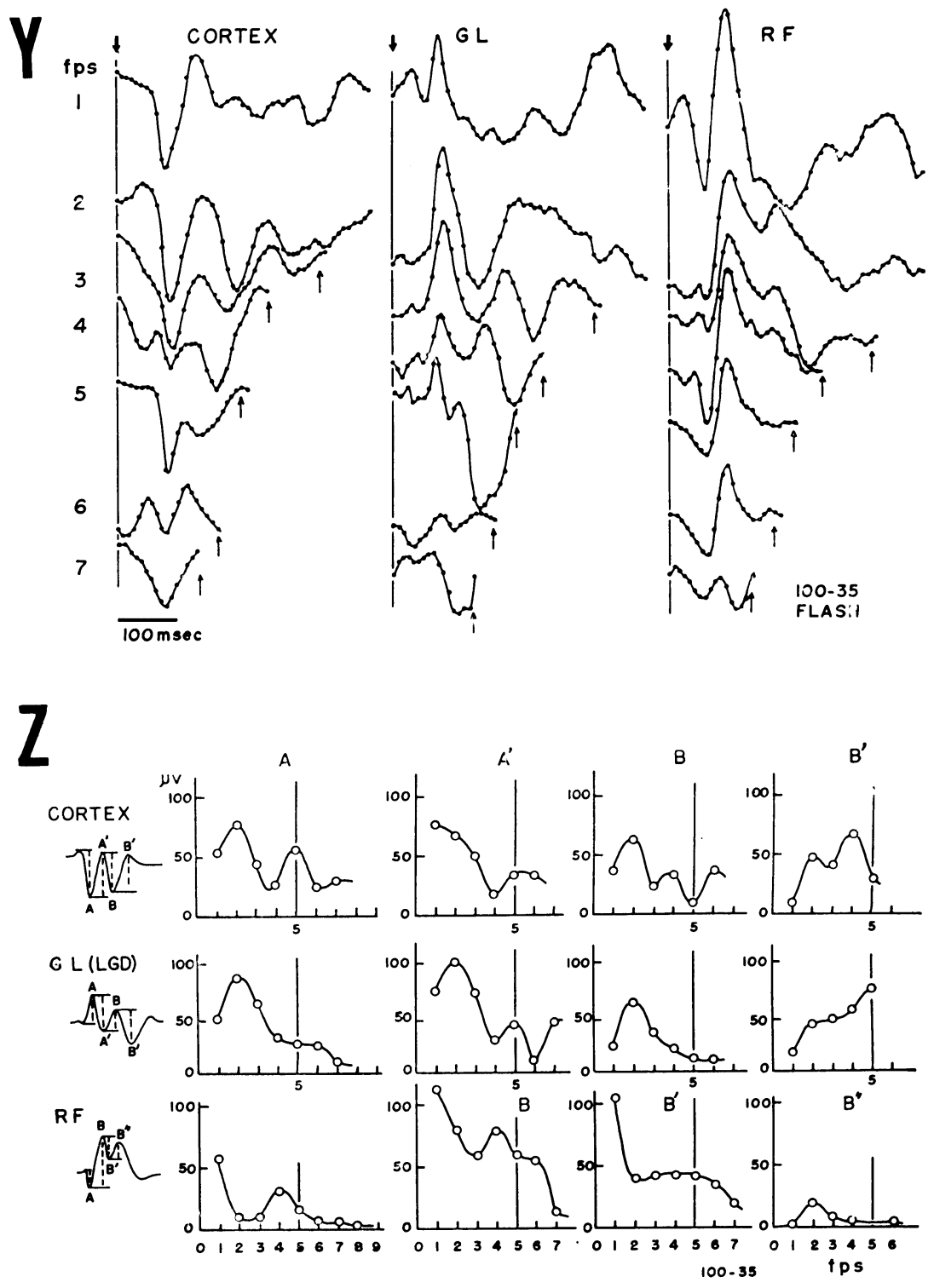

FIG. 1.

maximum amplitudes were observed at 1 and $4 \mathrm{f} / \mathrm{sec}$ in the $\mathrm{A}$ and $\mathrm{B}$ potentials, at 1 and 3 to $5 \mathrm{f} / \mathrm{sec}$ in the $B^{\prime}$ potential and at $2 \mathrm{f} / \mathrm{sec}$ in the $B^{\prime \prime}$ potential. In the visual cortex, enhanced responses were seen at 2 and $5 \mathrm{f} / \mathrm{sec}$ in the initial surface positive $A$ potential, at 1 and $5-6 \mathrm{f} / \mathrm{sec}$ in the following negative $A^{\prime}$ deflection and at 2 and $4 \mathrm{f} / \mathrm{sec}$ in the second positive $B$ and negative $B^{\prime}$ potentials. The GL activity in this instance was characterized by the $2 / \mathrm{sec}$ acti- 

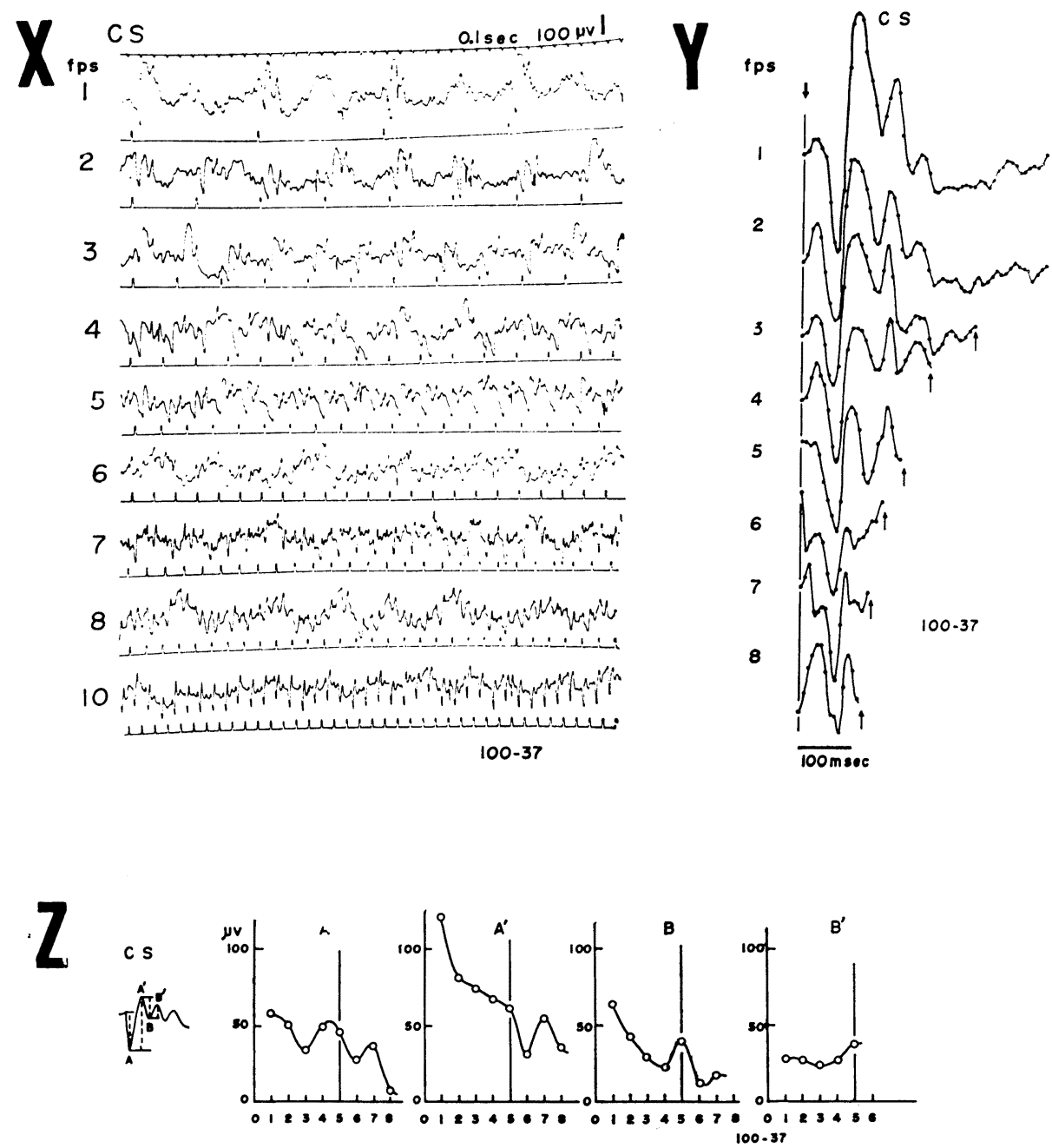

FIG. 2. Patterns of response in the superior colliculus (CS) to various flash frequencies. $\mathrm{X}$ : Ink records. $\mathrm{Y}$ : Average response time-contours. $Z$ : Amplitudefrequency diagrams of each component.

vity and the slight $5 / \mathrm{sec}$ activity, while the $\mathrm{RF}$ was characterized by the 1 or 2 and $4 / \mathrm{sec}$ activities. Cortical response patterns appear to be a mixture of both GL and RF, since the enhanced activities at $2 \mathrm{f} / \mathrm{sec}$ in the $\mathrm{A}, \mathrm{B}$ and $\mathrm{B}^{\prime}$ potentials and at $1 \mathrm{f} / \mathrm{sec}$ in the $A^{\prime}$ potential seem to be reflections of the characteristic activities of corresponding frequencies in GL and RF, while those at $5 / \mathrm{sec}$ in the $\mathrm{A}$ and $\mathrm{A}^{\prime}$ potentials and at $4 / \mathrm{sec}$ in the $\mathrm{B}$ and $\mathrm{B}^{\prime}$ potentials of the cortex seem to correspond with the characteristic activity of GL and RF, respectively. 
FIG. 3 illustrates the average patterns of five cases in the cortex, three cases in GL and RF and two cases in CS obtained under the same experimental conditions. With regard to the potentials in GL, the specific system, enhancements were observed at $1-2 \mathrm{f} / \mathrm{sec}$ in the $A$ potential, at $2 \mathrm{f} / \mathrm{sec}$ in $A^{\prime}$, at 2 and $5-6 \mathrm{f} / \mathrm{sec}$ in $\mathrm{B}$, and at $1 \mathrm{f} / \mathrm{sec}$ in $\mathrm{B}^{\prime}$. The activity of the $A$ potential in $R F$ did not indicate a monotonously decreasing pattern as in that of GL and CS,

A
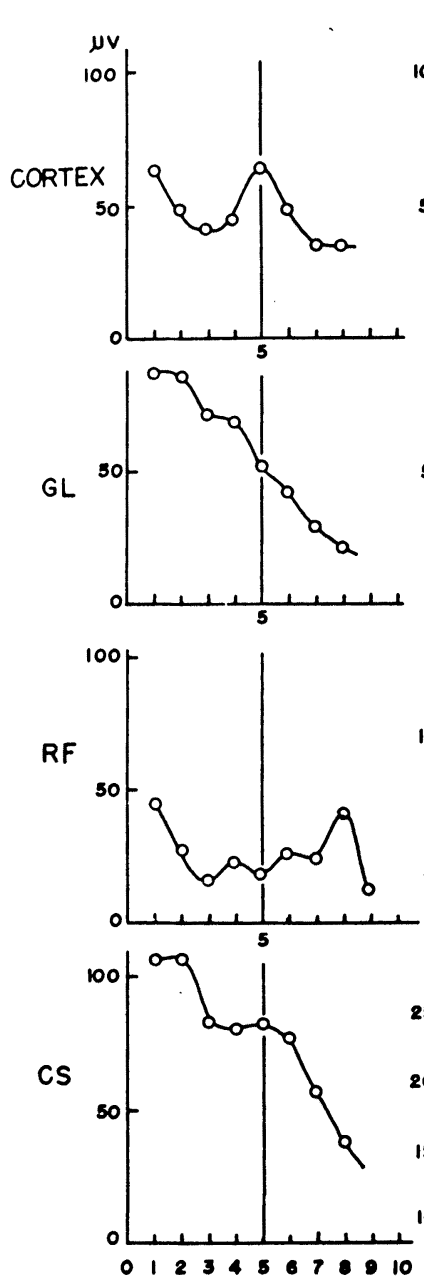

$A^{\prime}$
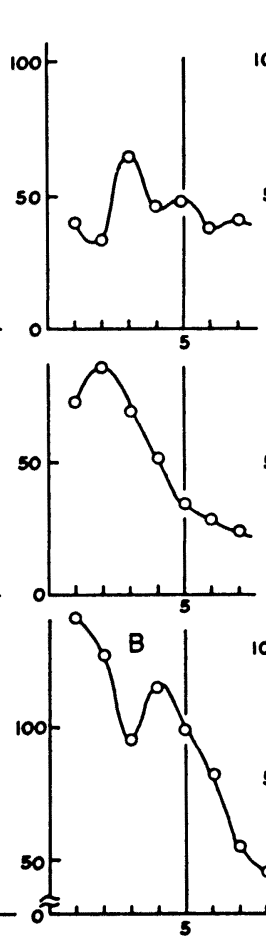

B

$B^{\prime}$ 
but it was enhanced at 1 and $8 \mathrm{f} / \mathrm{sec}$. Enhanced activities in $R F$, the nonspecific system, were elicited by stimulations of 1 and $4 \mathrm{f} / \mathrm{sec}$ in the $\mathrm{B}$ potential, by 1 and $3-5 \mathrm{f} / \mathrm{sec}$ in $\mathrm{B}^{\prime}$, and by $2 \mathrm{f} / \mathrm{sec}$ in $\mathrm{B}^{\prime \prime}$. Though both activities in GL and RF were characterized in common, therefore, by enhanced activity at 1 or $2 / \mathrm{sec}$ in the four potentials, distinct differences were revealed in such A potential activities that appeared a monotonous deterioration in GL and approximately flat trough at $3-7 / \mathrm{sec}$ following enhancements at 1 and $8 / \mathrm{sec}$ in $\mathrm{RF}$ and also in such $\mathrm{B}$ potential activities that followed a slight hump at 5$6 / \mathrm{sec}$ in GL and a distinct one at $4 / \mathrm{sec}$ in $\mathrm{RF}$.

In the cortical responses, maximum amplitudes were obtained at 1 and 5 $\mathrm{f} / \mathrm{sec}$ in the A potential, at $3 \mathrm{f} / \mathrm{sec}$ in $\mathrm{A}^{\prime}$, and at 1 and $4 \mathrm{f} / \mathrm{sec}$ in $B$. As noted above, the most parts of the cortical activity may be a reflection or a mixture of the subcortical activities, since the $1 / \mathrm{sec}$ activity may be qualified by both $\mathrm{GL}\left(\mathrm{A}\right.$ and $\mathrm{B}^{\prime}$ ) and $\mathrm{RF}$ ( $\mathrm{A}, \mathrm{B}$ and $\mathrm{B}^{\prime}$ ), while the 5 and $4 / \mathrm{sec}$ activities in the $A$ and $B$ potentials may be affected by $B$ potential in $G L$ and $R F$ respectively. The cortical $5 / \mathrm{sec}$ activity may possibly be due to the cortical activity itself, at least in part, since it was one of the predominant activities in the diagram while that in GL was subdominant one. This evidence suggests that the $5 / \mathrm{sec}$ activity in the early response $A$ of the cortex is partly influenced by the specific activity, whereas the later ones such as $B$ and $B^{\prime}$ are affected by the nonspecific activity. The amplitudes of the $A$ and $A^{\prime}$ potentials of GL and CS decayed with increasing frequency though there were some variabilities. This tendency was very similar to that of the retina (MIMURA and SATo, 1965), indicating little modification in the information from the retinal activity. Other responses in CS were observed as enhancements at $5 \mathrm{f} / \mathrm{sec}$ in the $A^{\prime}$ and/or $A$ potential and at 3 and $5-6 \mathrm{f} / \mathrm{sec}$ in $B$, which may correspond with the patterns of the specific system, whereas $1 / \mathrm{sec}$ in $\mathrm{A}$ and $\mathrm{A}^{\prime}$ may be related to both the specific and nonspecific systems.

2. Repetitive electrical stimulation of $G L$ and $R F$. Nervous impulses originated from the retina will be transmitted to the cerebral cortex via mainly two routes, i.e. the specific and nonspecific pathways. In order to elucidate their frequency characteristics in the cortex which originate from GL or RF, the response patterns induced by stimulation to $G L$ and $R F$, respectively, were studied. By this means, the cortical activity via GL or RF among the photically induced activities can be observed separately.

a) GL stimulation. Definite responses in the visual cortex and feeble responses in RF were produced by electric GL stimulation (FIG. $4 \mathrm{X}$ ). The former were augmented distinctly by 3 and 5-6/sec GL stimulation, whereas no augmentation was observed in the motor cortex (FIG. $4 \mathrm{X}, \mathrm{Cm}$ ). Hence, these slow responses in the visual cortex may be considered as the augmenting response. The average time-contours of these responses in relation to the 


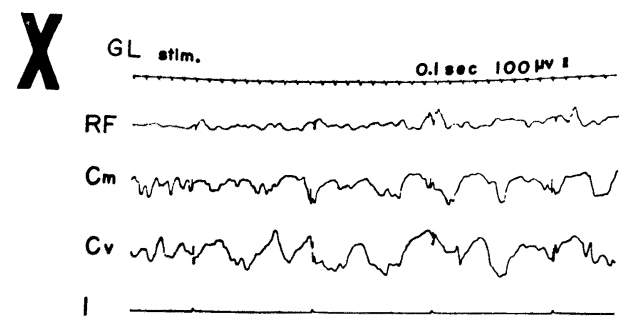

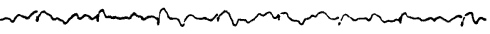

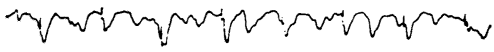

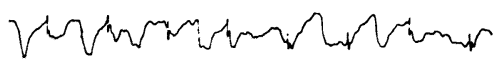

\section{7}

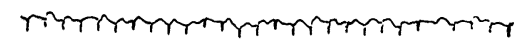

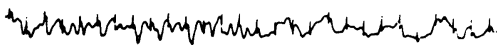

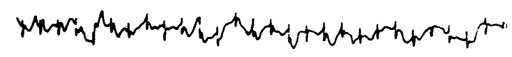

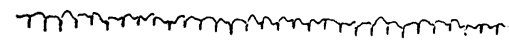

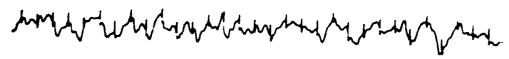

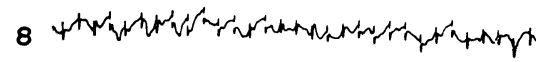

2

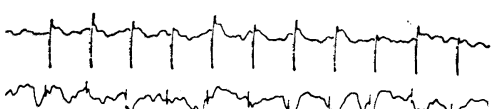

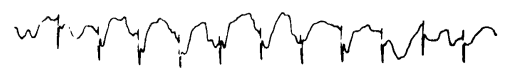

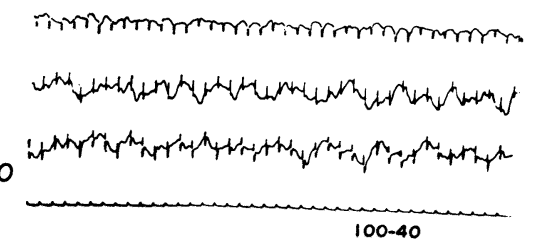

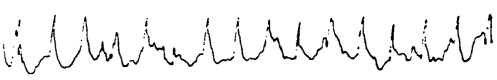

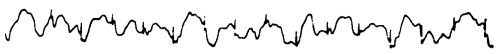

4

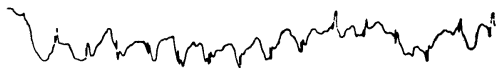

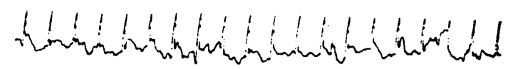

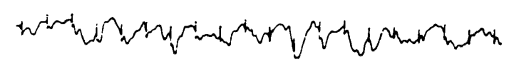

5

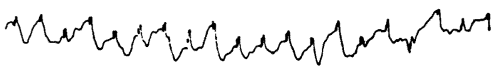

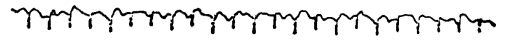

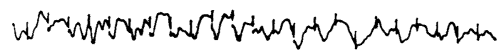
6

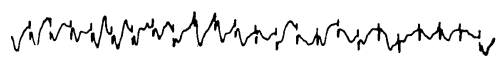

FIG. 4. Patterns of response in the cortex and RF evoked by repetitive electrical stimulation to GL. X: EEG ink records. Responses in the motor cortex (Cm) were highly contaminated, while the augmenting responses were very remarkable in the visual cortex $(\mathrm{Cv})$, especially at 3 and $5 / \mathrm{sec}$ stimulations. $\mathrm{Y}$ : Average response time-contours in the visual cortex (CORTEX) and RF. In order to eliminate stimulus artifacts, there are short blanks immediately prior to the potentials. Arrows denote stimulus pulse. $Z$ : Amplitude-frequency diagrams. I, $\mathrm{I}^{\prime}$, II and $\mathrm{II}^{\prime}$ indicate the activity patterns of potential $\mathrm{I}, \mathrm{I}^{\prime}, \mathrm{II}$ and $\mathrm{II}^{\prime}$ respectively. 

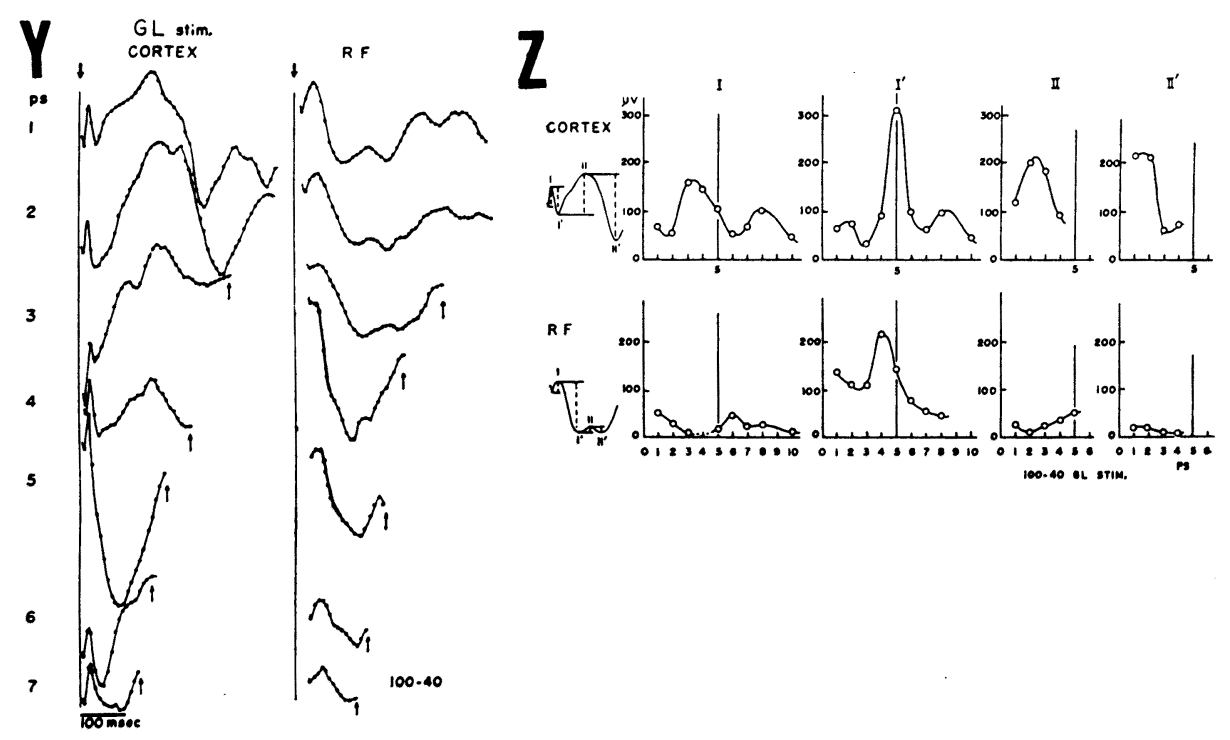

Fig. 4.

stimulating frequency are illustrated in FIG. 4Y. The cortical response exhibited two remarkable components, i. e., a surface negative potential with 34$39 \mathrm{msec}$ peak latency, which corresponds to the fifth wave elicited by stimulation of the optic pathway of cats (CHANG, 1952; MALIS and KRUGER, 1956), and a long-lasting surface negative shift with a $164-173 \mathrm{msec}$ peak latency. These two waves and the following deflections to each potential were provisionally called potentials $\mathrm{I}_{\text {, }} \mathrm{I}^{\prime}$, II and $\mathrm{II}^{\prime}$ respectively (FIG. $4 Z$ ). In RF, a slow upward deflection (52-61 msec peak latency), followed by a downward deflection accompanying a small upward deflection, was elicited. The amplitudes of these response components were plotted in relation to the stimulating frequencies (FIG. 4Z). It was observed in the cortical activity via GL that the I potential was enhanced by a $3-4 / \mathrm{sec}$ and $8 / \mathrm{sec}$ stimulation, $\mathrm{I}^{\prime}$ was enhanced markedly by $5 / \mathrm{sec}$ and slightly by 2 and $8 / \mathrm{sec}$ stimulation, II was enhanced by $2-3 / \mathrm{sec}$, and $\mathrm{II}^{\prime}$ was increased by $1-2 / \mathrm{sec}$ stimulation. The enhanced activity at $3-4 / \mathrm{sec}$ in the $\mathrm{I}$ potential and that at $5 / \mathrm{sec}$ activity in $\mathrm{I}^{\prime}$ correspond respectively to those in $\mathrm{A}^{\prime}$ potential, and in $\mathrm{A}$ and $\mathrm{A}^{\prime}$ (FIG. 3). These correspondences suggest that the cortical activity via GL is attributable mainly to the short latency components with characteristic frequencies of 3 and $5 / \mathrm{sec}$ in response to the flash stimulation.

RF activities via GL, however, were characterized by $4 /$ sec activity only in the $\mathrm{I}^{\prime}$ potential since other components were not conspicuous in their patterns.

b) RF stimulation. Part of the electroencephalographic ink records made during repetitive electric $R F$ stimulation at various frequencies and the aver- 
age response time contours in the motor cortex and GL are shown in Fig. 5X and $\mathrm{Y}$ respectively. In the cortex, a long-lasting, large and surface negative potential with $86-103 \mathrm{msec}$ peak latency was preceded by a small, surface negative one of short duration with $22-26$ msec peak latency, which sometimes

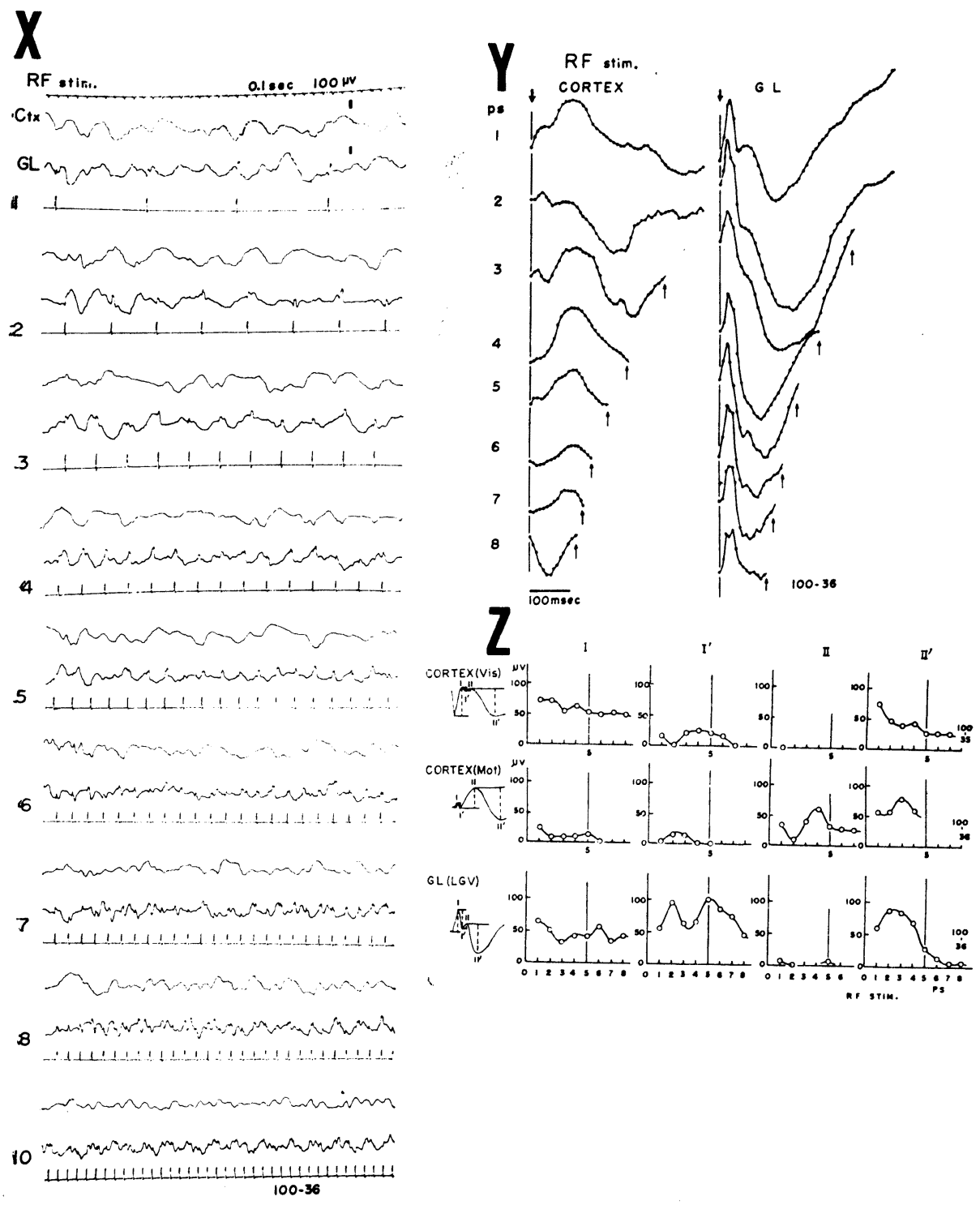

FIG. 5. Patterns of response in the cortex and GL to repetitive RF stimulation. $\mathrm{X}$ : EEG ink records of the visual cortex (Ctx) and GL during 1 to $10 / \mathrm{sec} \mathrm{RF}$ stimulation. Numerals on the left indicate the stimulating frequency. $Y$ : Average response time-contours. $Z$ : Amplitude-frequency diagrams in GL, visual (Vis) and motor cortex (Mot). 
could not be readily shown on the figure. In GL, a sharp and upward deflection followed by a small upward deflection was observed with peak latencies of 17-26 and 65-78 msec respectively. These potentials that preceded or followed in the cortex and GL were named provisionally as potential I and II respectively, while the surface positive one in the cortex and the downward deflection in GL, which followed I and II, were named as $\mathrm{I}^{\prime}$ and $\mathrm{II}^{\prime}$ (FIG. 5Z). Their average amplitudes with respect to the stimulating frequencies were depicted in FIG. 5Z. The responses in the visual cortex were only slightly enhanced respectively by $3-5$ and $1 / \mathrm{sec} R F$ stimulation in the $\mathrm{I}^{\prime}$ and $\mathrm{II}^{\prime}$ potentials, and a trace of elevation by a $4 / \mathrm{sec}$ in I and small $\mathrm{II}^{\prime}$ was observed, though in the motor cortex the II potential showed more outstanding enhancement by a $4 / \mathrm{sec}$ stimulation than in the visual cortex and the $\mathrm{II}^{\prime}$ potential did a raised activity at $3 / \mathrm{sec}$. The $4 / \mathrm{sec}$ activity was distinct in I of unanesthetized animal (FIG. 14, Vc) and was similar in frequency to that of the $B$ and $B^{\prime}$ potentials . of the anesthetized cortex brought out by flash stimulation (FIG. 3), whereas the $1 / \mathrm{sec}$ activity appeared in the $\mathrm{A}$ and $\mathrm{B}$ potentials. It seems, therefore, that the cortical activities via RF are mainly related to the late component in the visual response, and that their characteristic frequencies are 1 and $4 / \mathrm{sec}$, though the activity of the former frequency is related also to the early .component.

GL activities via $R F$ were characterized by 2 and $5 / \mathrm{sec}$ in $\mathrm{I}^{\prime}, 2-3 / \mathrm{sec}$ in $\mathrm{II}^{\prime}$, and, though slightly, 1 and $6 / \mathrm{sec}$ in I. Some of these activities were the same in their frequencies to those associated with the GL and visual cortex activities elicited by photic stimulation, which are, therefore, inherently specific ones.

\section{PART II. EVIDENCES IN THE UNANESTHETIZED RABBITS}

1. Repetitive flash stimulation. Responses evoked by flash stimulation of varying low frequencies $(1-15 / \mathrm{sec})$, contaminated by the background activities, were traced in the motor $(\mathrm{Mc})$, visual $(\mathrm{Vc})$ and limbic cortex (Lc), lateral geniculate body (GL), optic radiation (OR; $2 \mathrm{~mm}$ beneath the cortical surface), midbrain reticular formation (RF), Pulvinar (Pul), superior colliculus (CS) and, in a few cases, in the optic tract (OT). ERG was also recorded as an index of retinal activity. An example of the ink records and average response timecontours analyzed by ATAC-401 are depicted in FIG. $6 \mathrm{X}$ and Y, respectively. Typical wave forms of these potentials evoked by low frequency flash stimulations of 1 or $2.5 / \mathrm{sec}$ are illustrated in FIG. 7. The amplitudes of the waves, indicated as $A, A^{\prime}, B, B^{\prime}$ and $C$ respectively were measured at each frequency. Here, the $A$ potentials in GL, OR and Vc correspond to the primary response via the visual specific pathway. The response amplitude-frequency diagrams for various brain sites, illustrated in FIG. 8, were obtained by averaging eight 

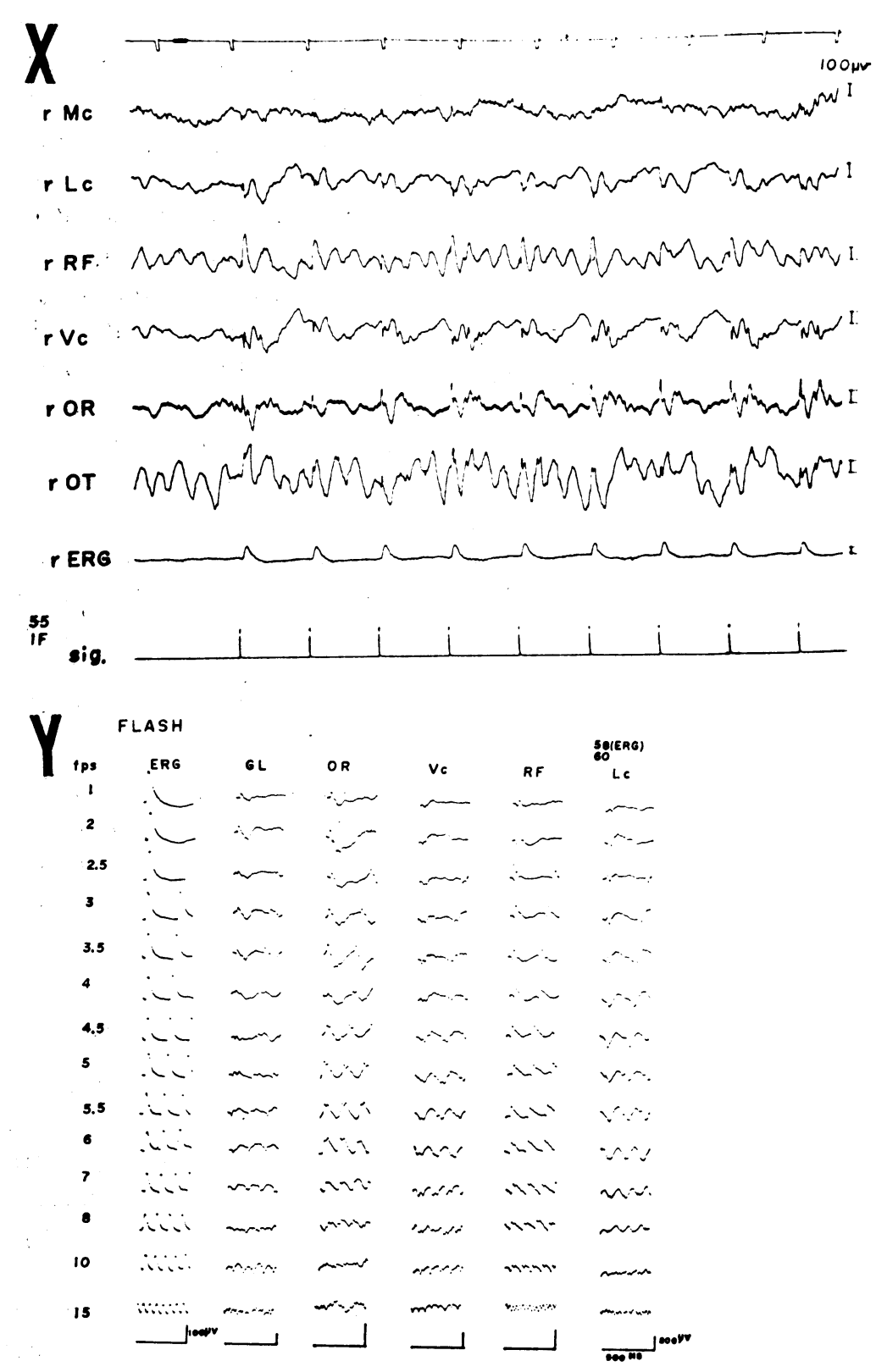

FIG. 6. An example of ink record during $1 / \mathrm{sec}$ flash stimulation (X) and average. time-patterns obtained by the Computer (ATAC-401) at various flash frequencies at various recording sites (Y). $\mathrm{X}$ : $\mathrm{r}$; right, Mc; motor cortex, Lc; limbic cortex, RF; mid-brain reticular formation, Vc; visual cortex, OR; optic radiation, OT; optic tract, ERG; electroretinogram, sig; flash stimulus. Time scale: $1 \mathrm{sec}$. Y : numerals on the left indicate flash frequency. Thirty responses were averaged for each response over the analysis time of $500 \mathrm{msec}$. 


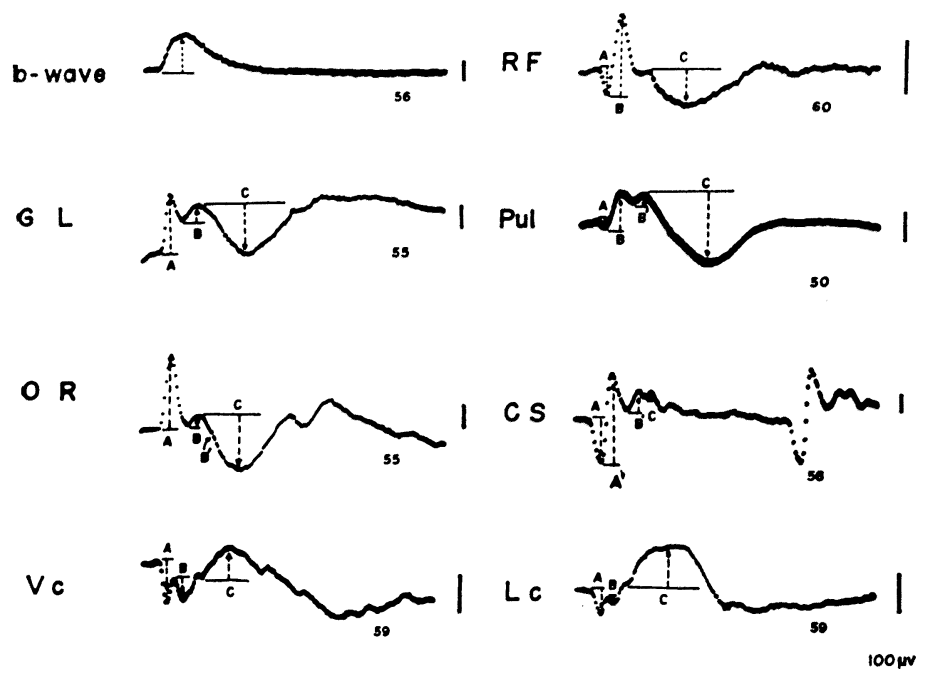

FIG. 7. Typical wave forms of responses evoked by flashing light. $\mathrm{A}, \mathrm{A}^{\prime}, \mathrm{B}, \mathrm{B}^{\prime}$ and $\mathrm{C}$ indicate the components of the evoked potentials. The amplitudes indicated by the broken line were measured for every average response at each flash frequency. In CS, two responses to successive stimulus of $2.5 / \mathrm{sec}$ stimulation were seen.

experiments in b-wave, five in GL, eight in $\mathrm{OR}$ and Vc, four in $\mathrm{RF}$, two in Pul, three in CS and seven in Lc. The amplitude of the electroretinal b-wave was found to monotonously decrease with increasing flash frequency as has already been verified in the previous report (MIMURA and SATO, 1965). However, almost all components of the recordings from the various sites showed peaks in the diagrams.

In the specific system, the A potential of GL was augmented at $4.5-6 / \mathrm{sec}$, and the $\mathrm{C}$ potential was enhanced at 2 and $3.5 / \mathrm{sec}$ stimulations, while the $\mathrm{B}$ potential did not show any appreciable enhancement except at $10 / \mathrm{sec}$. In Pul, the specific elaborative nucleus, the activities of the $B$ and $C$ potentials were similar, respectively, to those of the $A$ and $C$ potentials of $G L$, although no pronounced periodic changes of the activities were brought out in the $A$ and $B^{\prime}$ potentials.

On the contrary, in the nonspecific system, such as RF, no augmentations like those in GL were observed in either the A or C potential, except for a small hump at $1-2$ and $3.5 / \mathrm{sec}$ in the A potential. Augmentative activity was brought out only at less than $6 / \mathrm{sec}$ in the $\mathrm{B}$ potential. In view of the similarity in the activity changes, the activities in the cortical area appear to be dependent upon both the specific and nonspecific subcortical structures. That is, there were striking similarities of the A potential of GL with the A poten- 


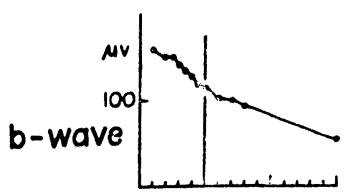

FLASH
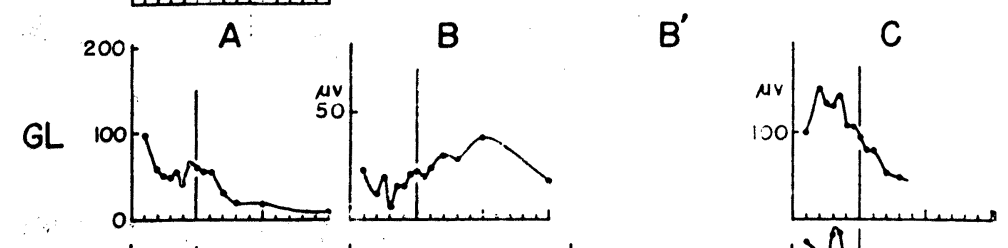

OR
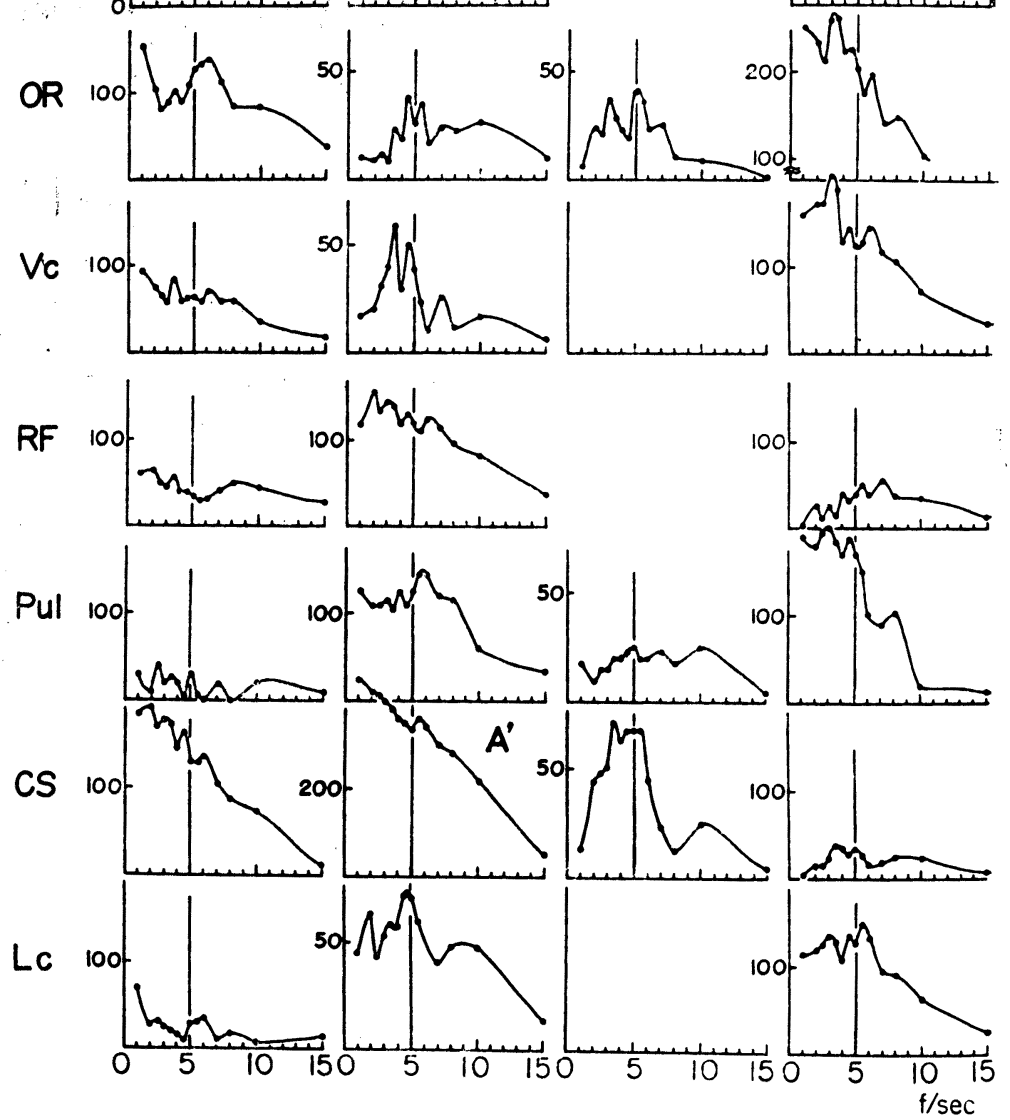

Fig. 8. Response amplitude-frequency diagrams of various components to flashing light. $\mathrm{A}, \mathrm{A}^{\prime}, \mathrm{B}, \mathrm{B}^{\prime}$ and $\mathrm{C}$ : wave components of the evoked potential shown in Fig. 7. Ordinates: amplitude. Abscissae: flash frequency. Absence of diagram for $\mathrm{B}^{\prime}$ of $\mathrm{GL}$ and $\mathrm{RF}$ means that this potential was not recognizable. Where only the scale is shown for $\mathrm{B}^{\prime}$ of $\mathrm{Vc}$ and $\mathrm{Lc}$ indicates that this component was too week to measure. See text for details. 
tials of OR and Lc. Furthermore, the A potential of Vc seemed to show characteristics which were a mixture of the $A$ potentials of both GL and RF, since the A potentials of Vc, GL and RF all demonstrated the highest activity at 1 or $2 / \mathrm{sec}$ stimulation and summation of the enhanced $\mathrm{A}$ potential activity of GL at about $4.5-6 / \mathrm{sec}$ and the diminutive one of $\mathrm{RF}$ at about $4-7 / \mathrm{sec}$ will form a plateau-like activity similar to that in Vc at about this same frequency range. Augmentations in the $B$ potential of $O R$ and $V c$ at such low frequencies as 3.5 and $4.5 / \mathrm{sec}$ seem to be a reflection of the activities in the B potential of RF at the corresponding frequency, and the peaks in OR at $5.5 / \mathrm{sec}$ may be due in part to the enhanced activity of GL at $4.5-6 / \mathrm{sec}$. Thus, the $\mathrm{B}$ potentials of $\mathrm{OR}$ and $\mathrm{Vc}$ were more intensely affected by the nonspecific activity. The enhanced activities of the $B$ potential in Vc, OR, and Lc at $10 / \mathrm{sec}$ may be related to that of the $B$ potential in $G L$ as well as the similar activity of the $\mathrm{B}^{\prime}$ potential in Pul and CS, too. The $\mathrm{B}$ and $\mathrm{C}$ potential activities of Lc were somewhat peculiar because of the dominancy of the activity at about $5 / \mathrm{sec}$. The activities of the $A$ and $A^{\prime}$ potentials in $C S$, which showed approximately a monotonous declination, were in agreement with the $\mathrm{A}$ and $\mathrm{A}^{\prime}$ potentials in the previous findings in the anesthetized state. As a whole, it is evident that (i) characteristic activity changes were shown in each of the specific and nonspecific subcortical structures, (ii) activities in the cortical areas were reflected by those of the two subcortical systems, and (iii) there may be a peculiar activity change in the limbic system.

2. Repetitive electrical stimulation of $G L$ and $R F$. In the above findings, the cortical activities were divided into specific and nonspecific activity changes on the basis of similarity in the frequencies of augmentations. Whether this similarity is really of GL and RF origin or not was confirmed by the behavior of the activities in response to GL and RF stimulations.

Markedly augmenting responses were elicited by electrical stimulation of GL (FIG. 9X). The average evoked responses in OR, Vc, RF and Lc elicited by stimulation of various frequencies are shown in FIG. 9Y. The wave forms of the responses to $1 / \mathrm{sec}$ stimulation and the amplitudes of the response components are indicated as $I_{0}, I_{1}, I^{\prime}$, II, III and IV potentials in FIG. 10. The amplitude-frequency diagrams of each of these components in various sites derived from averaging four cases in $\mathrm{OR}$ and $\mathrm{Lc}$, and three cases in Vc and $\mathrm{RF}$ under the same experimental conditions were presented in FIG. 11. Maximal responses of short latency were brought out respectively in $\mathrm{OR}(\mathrm{I})$ and Vc $\left(\mathrm{I}_{0}\right)$ at about 5.5 and $5-5.5 / \mathrm{sec}$ stimulation and a $7 / \mathrm{sec}$ and $5.5-7 / \mathrm{sec}$ stimulation in II and I. Augmentation at similar frequencies was observed in the I and I' potentials of RF and the I and III of Lc though a few peaks responses of the IV potential in OR and Lc and II in Vc, the slow component, occurred by $3.5 / \mathrm{sec}$ stimulation. 

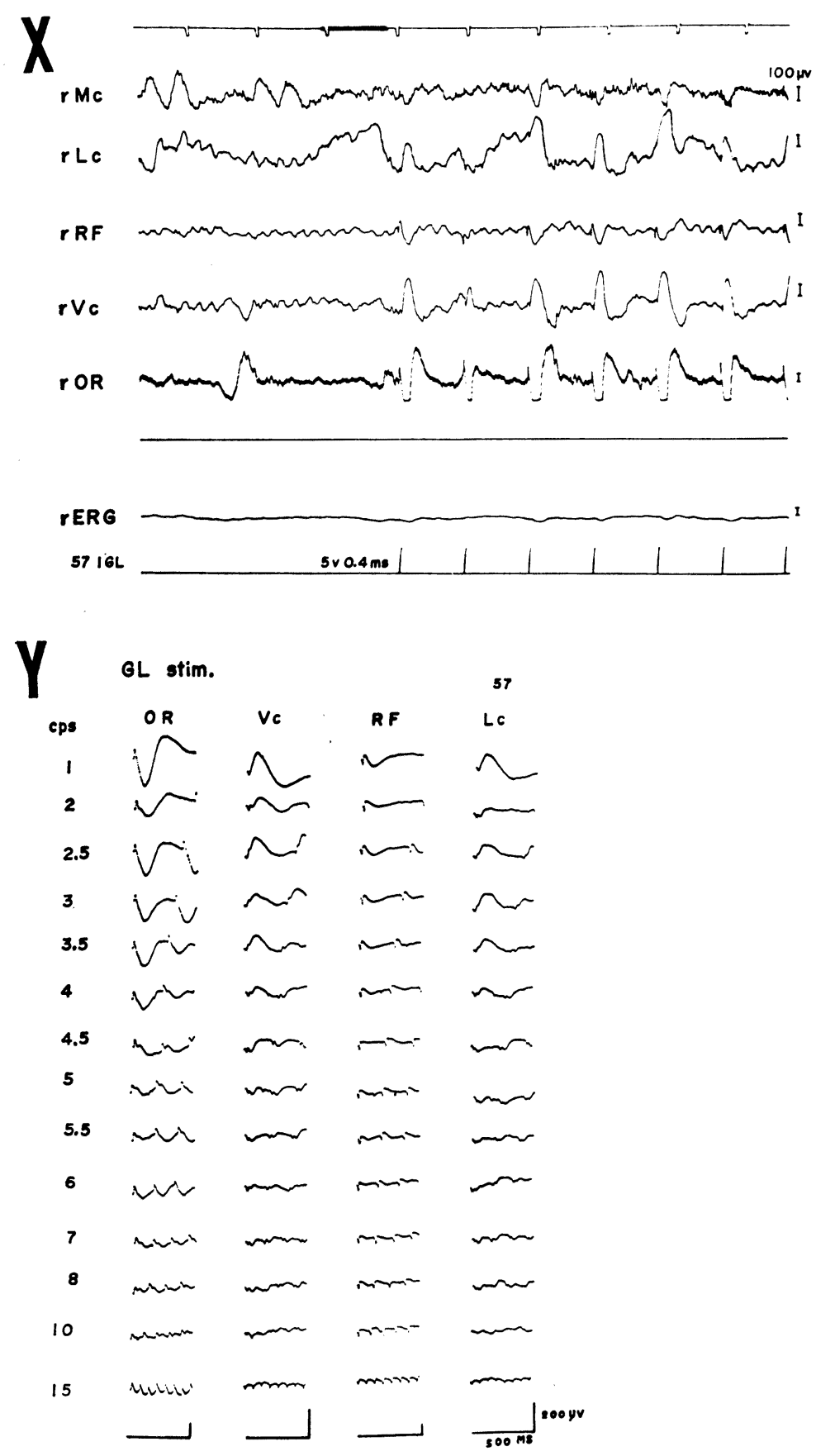

FIG. 9. An example of repetitive electrical GL stimulation. $\mathrm{X}$ : Ink records at $1 / \mathrm{sec}$ GL stimulation. Except in Mc and ERG, marked responses were observed in every site, even in Lc. Y: A series of average responses to GL stimulations of various frequencies. 
G L stim.
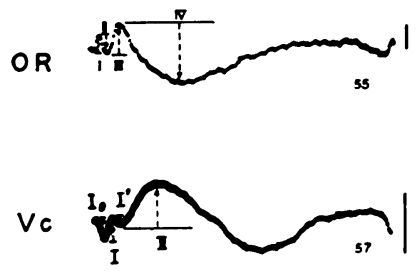

FIG. 10. Average responses in various sites to single GL stimulation. Amplitudes indicated as $\mathrm{I}_{0}, \mathrm{I}$, $I^{\prime}$, II, III and IV components were measured in the same fashion as in RF

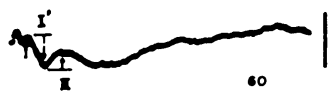
the case of flash stimulation.

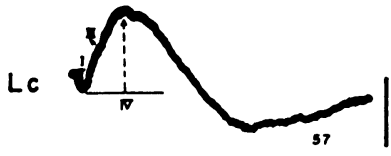

GL stim.
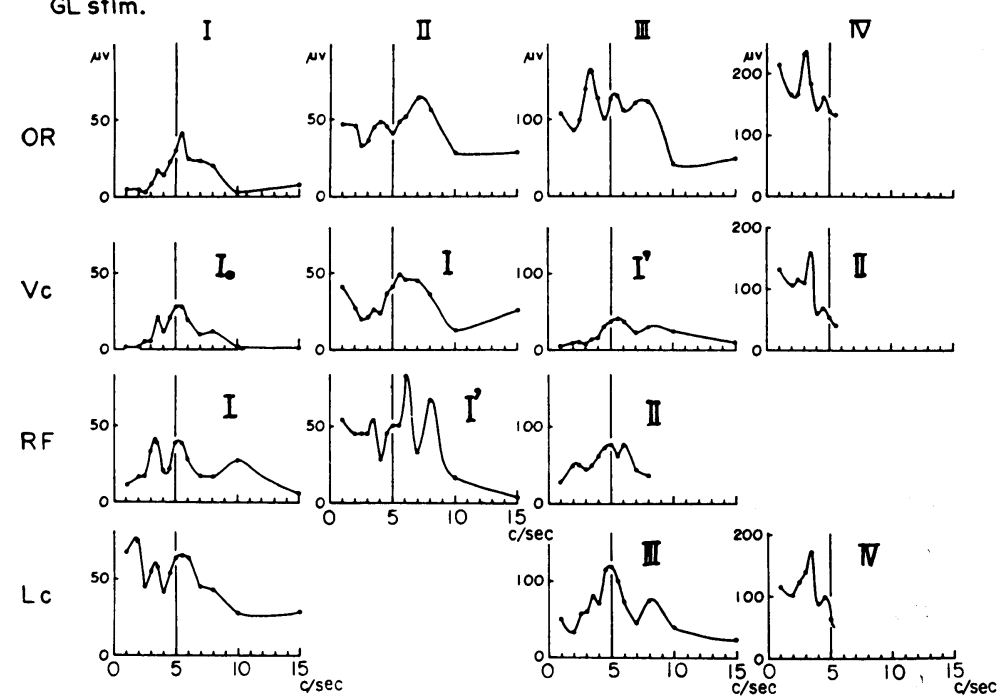

FIG. 11. Summarized amplitude-frequency relation in response to GL stimulation. Early potentials in the specific structures were augmented at 4 to $7-8 / \mathrm{sec}$ and late slow components were enhanced at $3-3.5 / \mathrm{sec}$.

appeared additionally in these sites. In addition to these augmentations, other augmented activities were exhibited in RF and Lc at 3-3.5/sec, which seemed to occur also in Vc and OR slightly. The III potential in OR and Lc, $\mathrm{I}^{\prime}$ in Vc and II in $\mathrm{RF}$ showed a maximum peak at about 5/sec, except for a peak at $3.5 / \mathrm{sec}$ in $\mathrm{OR}$ and peaks at $7-8 / \mathrm{sec}$ in $\mathrm{OR}, \mathrm{Vc}$ and Lc. Markedly enhanced 
$X$

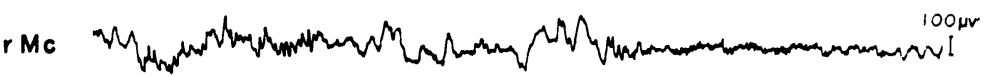

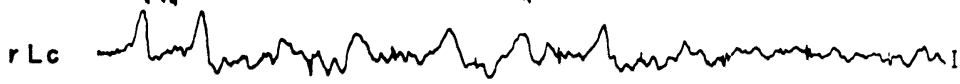

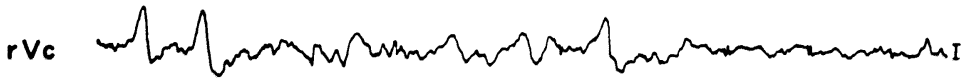

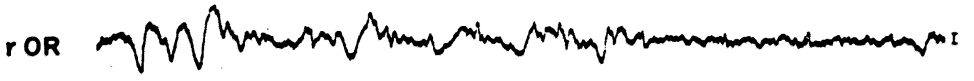

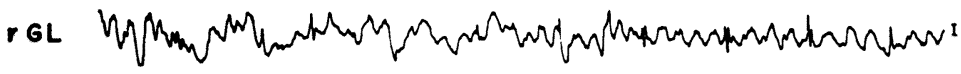

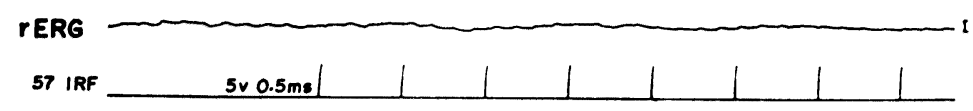

Y

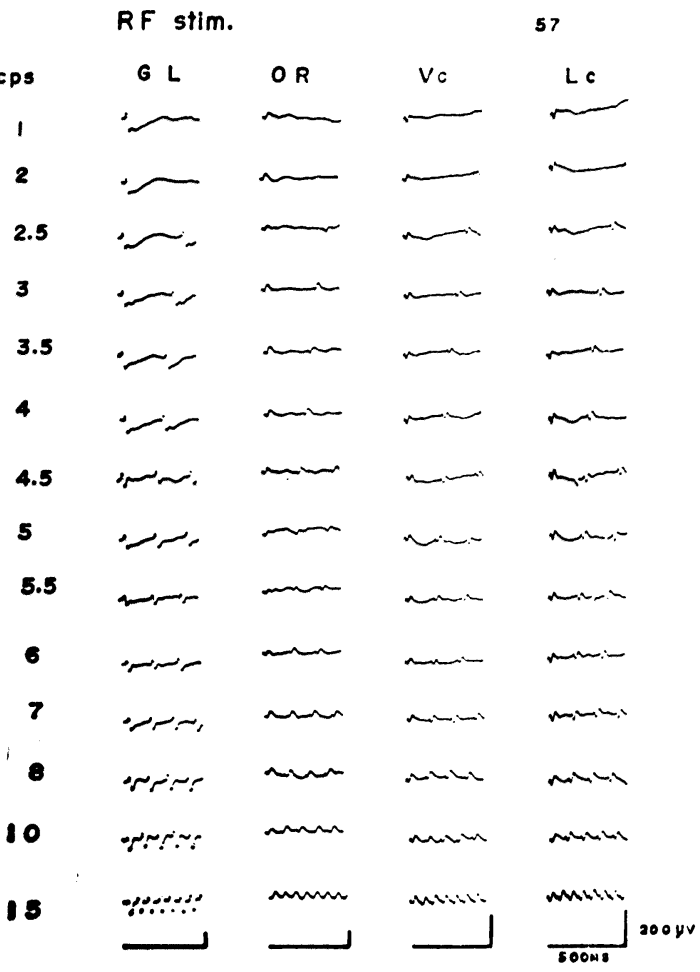

FIG. 12. A case of low frequency repetitive $R F$ stimulation $(1-15 / \mathrm{sec})$. $\mathrm{X}$ : Ink record at $1 / \mathrm{sec} \mathrm{RF}$ stimulation. Pulse-like responses appeared in all tracings but $\mathrm{a}$ remarkable slow component was not observed as compared with GL stimulation. Y: Averaged responses in various recording sites to RF stimulation. 
RF stim.
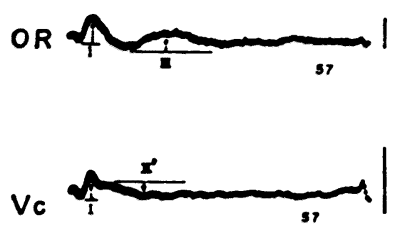

FIG. 13. Averaged wave forms of the responses to single RF stimulation. Amplitudes of I, I', II, II and III components were measured

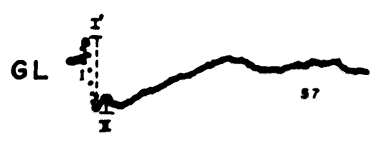
in the same way as in the case of flash or GL stimulations.

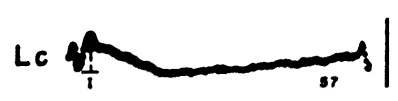

calib. : $100 \mathrm{wr}$

RF stim.

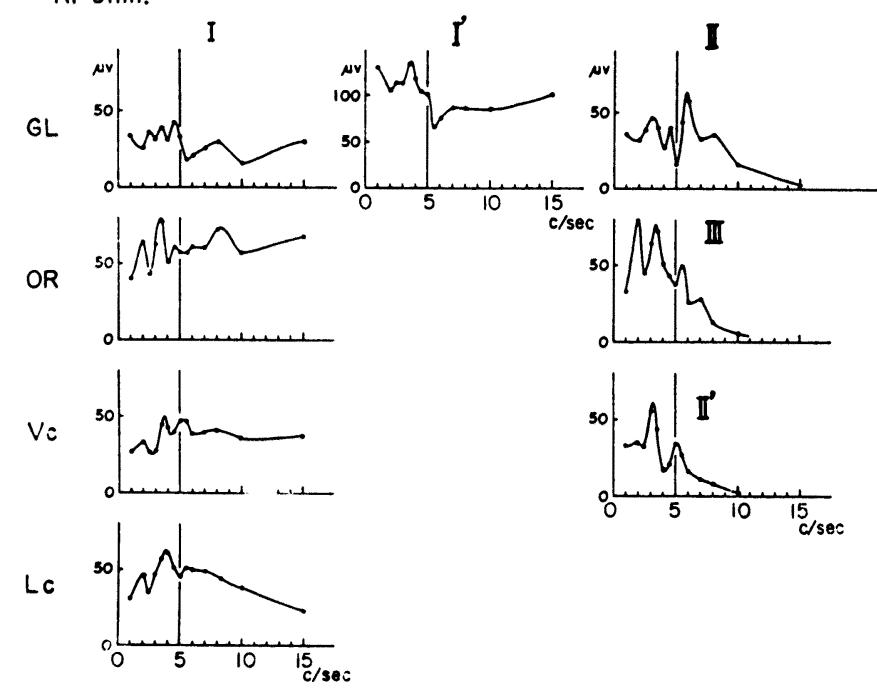

FIG. 14. Summarized amplitude-frequency diagrams to low frequency repetitive $\mathrm{RF}$ stimulation $(1-15 / \mathrm{sec})$. I, I', II, II' and III : The wave components as shown in FIG. 13. Contrary to GL stimulation, peaks showing augmentation of responses did not appear at 4 to $7-8 / \mathrm{sec}$ but rather at less than $5 / \mathrm{sec}$, although late components such as III were slightly similar with those of GL stimulation. 
On the contrary, the response patterns in RF stimulation differed considerably from those in GL stimulation. An example of the records is shown in FIG. 12X, where no remarkable slow responses are recognized although there are spike-like potentials. In FIG. 12Y, the average response time-patterns obtained by the ATAC- 401 are depicted. Their wave forms and the amplitudes of the wave components are indicated as $\mathrm{I} \mathrm{I}^{\prime}, \mathrm{II}, \mathrm{II}^{\prime}$ and III potentials in FIG. 13. In their amplitude-frequency diagrams (FIG. 14), no prominent activities of $I$ and $I^{\prime}$ potentials at 5 to $7 / \mathrm{sec}$ such as seen in GL stimulation were observed, but the activities at frequencies lower than $5 / \mathrm{sec}$ were strengthened in every recording site. Even in the long-lasting III and $\mathrm{II}^{\prime}$ potentials of OR and Vc, this tendency persisted, though 5 or $5.5 / \mathrm{sec}$ activities were strengthened slightly. However, the small II potential preceded by the primary upward and downward deflections in GL responded more greatly at 5.5-6/sec than at the above lower frequencies.

These confirm the fact that augmentations at such relatively higher frequencies as 5 to $7-8 / \mathrm{sec}$ are associated chiefly with the specific activity, while those at lower frequencies of less than about $5 / \mathrm{sec}$ depend mainly upon the non-specific activity. However, the augmenting responses may also be included in the lower frequency activities as shown in the latest potentials in GL stimulation.

\section{DISCUSSION}

As shown at the beginning in the peak latency, it seems strange that impulses from the retina reach to $R F$ faster than GL, and that the A potential of RF was very similar to that of $\mathrm{CS}$ in its wave form, latency and amplitude. It may be possible, therefore, that the response recorded from RF may not be the response of $\mathrm{RF}$ itself but rather be due to current leakage from CS. However, VoN GUDDEN (1881) and GilliLAN (1941) have demonstrated fibers running from the optic tract to a number of midbrain nuclei in rabbits. The potential with a shorter latency than that of the GL response may be elicited through this tract. In spite of the similarity in the potential itself, the activity of the potential $A$ of $R F$ in relation to the flash frequency was markedly different from that of CS (see FIG. 3 and 8). Hence the possibility of leakage from CS can be denied.

It is well known that the evoked potential is affected by anesthesia. In general, when anesthesia is not so deep, the transmission of impulses to the brain through the primary sensory pathway is not disturbed (FRENCH et al., 1953; BRAZIER, 1954) though reduction is recognized in the amplitude of the potential (ARDUINI and ARDUINI, 1954). However, there have been paradoxical findings on the components which follow the primary response. Cortical evoked responses with medium latency $(12-30 \mathrm{msec})$ produced by stimulation of the 
sensory nerve or reticular structure have been observed only in the unanesthetizedis state (MORUzZI and MAGOUN, 1949; STARZL and MAGoun, 1951) and all components except for the primary response provoked by sensory stimulation are reduced or disappear during anesthesia (ARDUINI and ARDUINI, 1954). On the other hand, the "secondary discharge" of FORBES and MORISON (1939) is augmented by barbiturate anesthesia. In order to define the components of the evoked potentials observed in this paper, some average responses obtained during the anesthetic state and those obtained during the unanesthetic state by the same method are shown in FIG. 15 for comparison. Each of the A and
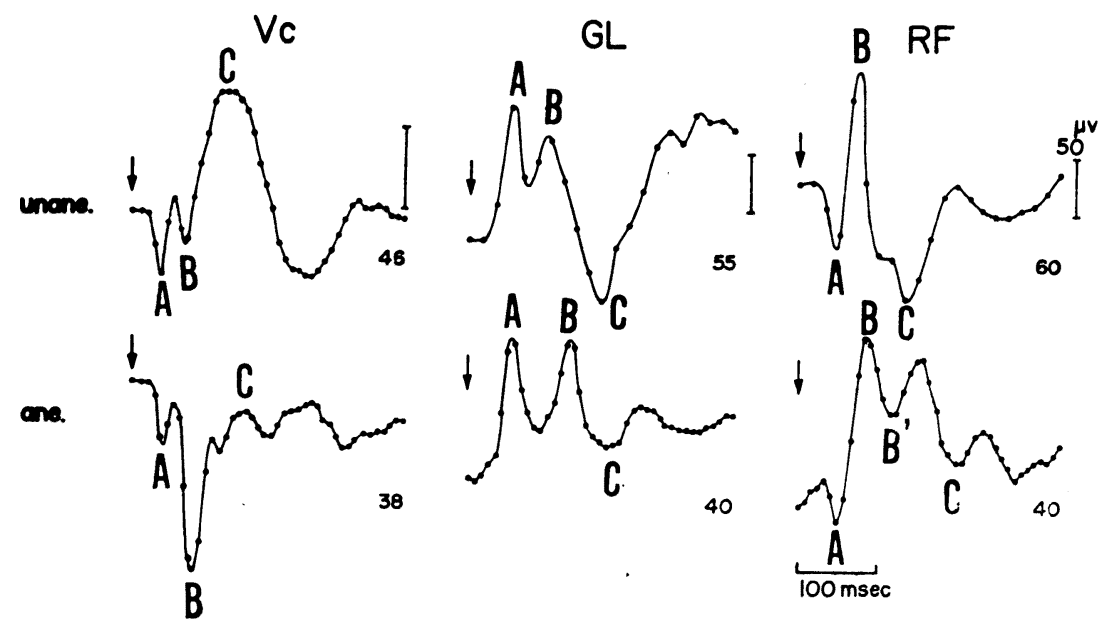

Fig. 15. Comparison of average response time-patterns under anesthetized (ane.) and unanesthetized states (unane.). These average responses to a single flash (indicated by arrow) were obtained by averaging ten responses. Calibra. tion is the same in each recording site under both anesthetized and unanesthetized states $(50 \mu \mathrm{V})$. For details see text.

$B$ potentials under anesthesia correspond respectively to those in the unanesthetized state. The $B^{\prime}$ potential of RF under anesthesia is distinct, whereas it is not so clear in the unanesthetized state. In this figure, the most conspicuous differences are seen in the evoked potentials in the visual cortex. Though the A potentials in both states are very similar in their configurations, the B potential was shifted tremendously to the positive side much prolonged under anesthesia, showing that it coincides with the "secondary discharge" mentioned above. Contrarily, the $C$ potential attenuated to be practically obscured under anesthesia. The potential may correspond to the "secondary potential" of FUSTER and Docter (1962). In GL, the B potential increased in size by anesthesia, while the $C$ potential was reduced considerably. The peak latencies of both were prolonged. In $\mathrm{RF}$, the amplitude of the $\mathrm{A}$ potential was decreased slightly here, demonstrating that the evoked responses in $\mathrm{RF}$ are reduced or 
disappear in the anesthetized state (ARDUINI and ARDUINI, 1954).

In the previous paper (MIMURA and SATO, 1965), it was found that amplitudes of the slow components of the cortical potential of the rabbit evoked by repetitive flash stimulation were augmented at about 3 and $5 / \mathrm{sec}$ while those of the b-wave of ERG were monotonously declined with increasing flash frequency. Such augmentations at definite frequencies as verified by peaks in the frequency response curve indicate that the periodic activity is more predominant at these frequencies than others (SATO et al., 1961). Therefore, it seems reasonable to assume that such cyclic activity changes take place within the central nervous system while not in the retina. Furthermore, it was found that in both the anesthetized and unanesthetized states the cyclic activity originates at least in part from the subcortical specific and nonspecific systems, although some differences were recognized as will be discussed later. Under anesthetized condition, in view of the augmentation of the responses in the cortex to repetitive flash stimulation and repetitive GL or RF stimulation, the cyclic activities appeared at $5-6 / \mathrm{sec}$ is attributed to $\mathrm{GL}$, the specific system, and those at $4 / \mathrm{sec}$ to $\mathrm{RF}$, the nonspecific system. On the other hand in the unanesthetized situation, the most characteristic periodic activities were seen at 1 and $4.5-6 / \mathrm{sec}$ in the peaks of the $\mathrm{A}$ potentials in GL and $\mathrm{OR}$, and at about $2-3.5 / \mathrm{sec}$ in the peaks of the $\mathrm{C}$ potentials in GL, OR and visual cortex. The latter peak of the A potential was ascertained by the activities of the early two components in GL stimulation and the peak of $C$ potential by the late two potentials so that these activity behaviors of $A$ and $C$ potentials are associated respectively with those of the specific afferents as well as under anesthesia. The activity at the relatively higher frequency of $4.5-6 / \mathrm{sec}$, which is attributable to the specific system only, may correspond to BIsHop's cyclic excitability change (1933) or the excitability cycle within the specific structure in other studies (CHANG, 1950, 1951; GASTAuT et al., 1951). On the other hand, the activities in $\mathrm{RF}$ in response to flash stimulation was characterized by moderate trough at $6 / \mathrm{sec}$ in the $\mathrm{A}$ potential and the vast augmentations in the $B$ potential at frequencies lower than about $5 / \mathrm{sec}$ as well as the inactive patterns at lower frequency in the $C$ potential in $R F$ as compared with the $C$ potential in the specific structures (GL, OR). Such activity patterns at lower frequency in the $\mathrm{A}$ and $\mathrm{B}$ potentials were confirmed also by the $\mathrm{I}, \mathrm{I}^{\prime}, \mathrm{II}^{\prime}$ and III potentials in response to RF stimulation. Every component at each recording site demonstrated the acceleration of peaks at less than $5 / \mathrm{sec}$. Consequently, it would not be unreasonable to assume that the activity pattern of RF might be conspicuous at frequencies lower than $5 / \mathrm{sec}$. In the unanesthetized state, however, a characteristic periodic activity was not demonstrated, because the activity patterns did not appear as one or two conspicuous peaks but as a group of several small peaks of nearly the same height both in repetitive flash and electrical stimulation. The activity patterns of the $\mathrm{B}$ and $\mathrm{B}^{\prime}$ poten- 
tials in GL, OR and Vc were too complicated to attempt classification as simply as in the case of the anesthetized state. However, in part, B and $B^{\prime}$ potentials appear to show a mixture or summation of $A$ potential activities in both the GL and RF. These activity changes in GL and RF show characteristic patterns for the specific and non-specific systems respectively and the property of the activity patterns of the cortex exhibit a mixture of patterns of both specific and non-specific systems. Many authors have demonstrated interactions between the specific and non-specific afferent systems at the cortical level. Some of them (JASPER and AJMONE-MARSAN, 1952; BREMER and Stoupel, 1959; NARIKASHVILI and MoNIAVA, 1959; LANDAU et al., 1961) demonstrated facilitations, whereas a few investigators observed occlusions in the primary evoked sensory potentials. Though no direct interactions were observed in these experiments, the amplitude-frequency diagrams produced by repetitive electrical stimulation to GL and RF showed that the cortical activity had properties characteristic to the two subcortical afferent systems. Furthermore, these characteristic activities in the specific and nonspecific systems may be attributable to the augmenting and recruiting-like responses respectively. If so, there must be an interaction between these two responses. Interactions between recruiting and augmenting phenomena were first denied by DEMPSEY and MORISON (1942), but were observed later by PARMA and ZANCHETTI (1956) and BROOKHART et al. (1957). However, the same authors postulated the fundamental differences between the augmenting and recruiting responses (DEMPSEY and MORISON, 1942; HANBERY and JASPER, 1953; BROOKHART and ZANChETTI, 1956). On the other hand, Bishop et al. (1961) did not think that these differences were very fundamental. KLEE and OFFENLOCH (1964) described the postsynaptic potentials accompanying the augmenting response as consisting of a primary response and a response of recruiting character. Such a combined nature of the responses is supported by the cyclic activities at the relatively lower frequency of about $1-2 / \mathrm{sec}$ which originate from both the specific and nonspecific activities as verified here.

The A and B' potentials of Pul did not indicate any characteristic pattern, but the activities of $B$ and $C$ were very similar to those of $A$ and $C$ of the specific structures, respectively. Therefore, it may be possible to consider the activity patterns of Pul, the specific elaborative or association nucleus, to be closely related with the specific activity. The A potential activities in Lc very resemble any other activity patterns but demonstrated unique features. This may suggest that they are related to the rhinencephalic synchronizing mechanism (GANGLOFF and MONNIER, 1956) or a pace maker activity of the septum (GREen and ARduini, 1954; MAYER and STUMPF, 1958; BrÚCKE et al., 1959; BRUGGE, 1965) that are independent from the above mentioned periodic activity systems. Further research on the relation between the cyclic activity changes and spontaneous "theta" rhythm of the rabbit will be dis- 
cussed in detail in a paper to follow (Mimura et al., 1965, 1967b).

In comparison of the activity behaviors in the unanesthetized state with those under anesthesia, the similarities between both states were divided into the following three groups: highly similar, different in part and not similar. The first group contains the $A$ and $A^{\prime}$ potential of $C S$ in flash stimulation and the I' and II potentials of Vc in GL stimulation. The second group consists of the $A$ potential of $G L, V c$ and $R F$, the $B$ potential of Vc and $R F$ in flash stimulation and the I potential of Vc in GL stimulation. All other potentials, i. e. the B potentials of GL due to flash; the I, I' and II potential of RF in GL stimulation; the I and II' potentials of Vc and the I, I' and II potentials of GL in RF stimulation, belong to the third group. Because of agreement with the fact that barbiturate anesthesia has more intense depressive effects on the reticular system than other structures (FRENCH et al., 1953; BRAzIER, 1954 ; ARduINI and ARduINI, 1954), the above classification suggests that the activities associated with the specific afferent impulses were resistant to anesthetics, whereas the deeper the components are related with RF, the more the activities are affected by anesthetics. Though points on the activity curves were scattered more widely in the anesthetized experiment $(1 / \mathrm{sec})$ than in the unanesthetized state $(0.5 / \mathrm{sec})$, the latter curves were more complicated than the former. In the $\mathrm{B}$ potential of $\mathrm{Vc}$, there appeared three peaks on the amplitude-frequency diagram. The intermediate peak at $4.5 / \mathrm{sec}$ corresponds to that at $4 / \mathrm{sec}$ in the anesthetized state, and the two peaks at 3.5 and $7 / \mathrm{sec}$ had been newly produced. Judging from the anesthetized effect, this B potential was defined as the "secondary discharge" as shown before. Although the "secondary discharge" is augmented under anesthesia, this potential as shown here in the unanesthetized state showed new activities depending upon the stimulating frequency. This paradoxical phenomenon can be explained by the following speculations. The "secondary discharge" had been investigated on the somatosensory response. However, the evoked potential of cat and monkey by brief flash stimulus has a very complicated form in the unanesthetized state as recently demonstrated (Hirota, 1964; Hughes, 1964; SteinberG, 1965). Further, the response in rabbits also has a complicated form such as in cat and monkey (IWASE et al., 1965; Mrmura et al., 1967a). Therefore, the B potential may not be the response of the same nature as the "secondary discharge" of FORBES and MORISON. In addition, MORISON suggested two afferent pathways from the brain stem for the cortical evoked responses with medium latency. One of them is an extrathalamic route and the other runs forward through the subthalamic structure and thalamus (personal communication with FRENCH, FRENCH, 1960). He pointed out that the " secondary discharge" may be due to the former. If this is so, it may be possible to speculate that the newly revealed activities of the $B$ potential in the unanesthetized state are caused 
via this latter route which is depressed during anesthesia. Also such reasoning may explain the cause for the new peaks produced in the I potential activity of Vc by RF stimulation in which no peaks were observed under anesthesia.

\section{SUMMARY}

The activity patterns (response amplitude-frequency diagram) of ten anesthetized and eleven unanesthetized rabbits brain evoked by repetitive flash stimulation of varying frequencies $(1-15 / \mathrm{sec})$ were observed with respect to the stimulating frequency in the lateral geniculate body $(\mathrm{GL})$, optic radiation* $(\mathrm{OR})$, midbrain reticular formation $(\mathrm{RF})$, Pulvinar* $(\mathrm{Pul})$, superior colliculus (CS) and visual (Vc) and limbic cortex* (Lc), wherein those in the starred sites were observed under unanesthetized situation only.

The activities in each of the specific and nonspecific structures presented characteristic patterns and in $\mathrm{Lc}$, too. In GL and $\mathrm{OR}$, the initial potential with short duration (A potential) was augmented at $4.5-6 / \mathrm{sec}$ flash stimulation and the slow component ( $\mathrm{C}$ potential) was enhanced at $2-3.5 / \mathrm{sec}$ which suggests cyclic activity changes at these frequencies. On the contrary, it was demonstrated that the activities of RF were characterized by 1 and $4 / \mathrm{sec}$ under anesthetized state and by vast augmentation at less than $5 / \mathrm{sec}$ under unanesthetized state, though no conspicuous cyclic property. In the Lc, an independent cyclic property from the above specific systems was observed. These observations were confirmed by the repetitive electrical stimulation to GL or $\mathrm{RF}$, suggesting that the augmenting and recruiting-like responses play a rôle at least in part.

The activity patterns associated mainly with the specific activity were not affected by anesthetic condition, while the activities or the potential components related closely with $\mathrm{RF}$ were most affected by anesthesia.

This research has been made possible through the support (DA-92-557-FEC-35764 and 37212) of the U.S. Department of Army and the stereotaxic instrument was donated by the Rockefeller Foundation (GA-BMR 5893).

\section{REFERENCES}

Arduini, A. And Arduini, M.G. Effect of drugs and metabolic alterations on brain stem arousal mechanism. J. Pharmacol. \& Exper. Therap., 110:76-85, 1954.

Bishop, G.H. Cyclic changes in excitability of the optic pathway of the rabbit. Amer. J. Physiol., 103 : 213-224, 1933.

Bishop, G.H., Clare, M.H. and Landau, W. M. The equivalence of recruiting and augmenting phenomena in the visual cortex of the cat. Electroenceph. clin. Neurophysiol., 13 : 34-42, 1961.

BraziER, M.A.B. The action of anesthetics on the nervous system. Brain mechanisms and consciousness, Blackwell Scientific Publications, Oxford, 163-199, 1954. 
Bremer, F. et Stoupel, N. Facilitation et inhibition des potentials évoqués corticaux dans l'éveil cérébral. Arch. int. Physiol., $67:$ 240-275, 1959.

Brookhart, J. M., Arduini, A., Mancia, M. and Moruzzi, G. Mutual facilitation of cortical responses to thalamic stimulation. Arch. ital. Biol., 95: 139-146, 1957.

Brookhart, J.M. AND ZANCHETTI, A. The relation between electro-cortical waves and responsiveness of the cortico-spinal system. Electroenceph. clin. Neurophysiol., $8: 427-444,1956$.

Brücke, F., Petsche, H., Pillat, B. And Deisenhammer, E. Ein Schrittmacher in der medialen Septumregion des Kaninchengehirnes. Pflügers Archiv ges. Physiol., 269 : 135-140, 1959.

BRUGGE, J.F. An electrographic study of the hippocampus and neocortex in unrestrained rats following septal lesions. Electroenceph. clin. Neurophysiol., 18: 36-44, 1965.

$\mathrm{C}_{\mathrm{HANG}}, \mathrm{H} .-\mathrm{T}$. The repetitive discharges of cortico-thalamic reverberating circuit. $J$. Neurophysiol., $13: 235-257,1950$.

CHANG, H.-T. Changes in excitability of cerebral cortex following single electrical shock applied to cortical surface. J. Neurophysiol., 14 : 95-111, 1951.

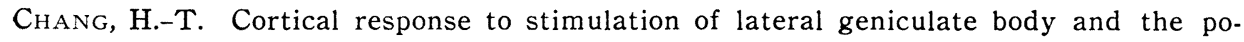
tentiation thereof by continuous illumination of retina. J. Neurophysiol., 15:5-26, 1952.

Dempsey, E. W. AND MORison, R.S. The production of rhythmically recurrent cortical potentials after localized thalamic stimulation. Amer. J. Physiol., 135: 293-300, 1942.

Fifková, E. And Muršala, J. Stereotoxic atlas for the cat, rabbit and rat. Bures, J., Petrán, M. And Zachar, J.: Electrophysiological methods in biological research. 1962, Prague, 426-467 Publishing House of the Czechoslovak Academy of Sciences.

Forbes, A. AND Morison, B. R. Cortical response to sensory stimulation under deep barbiturate narcosis. J. Neurophysiol., 2 : 112-128, 1939.

French, J. D., Verzeano, M. and Magoun, H. W. A neural basis of the anesthetic state. A.M. A. Arch. Neurol. \& Psychiat., 69: 519-529, 1953.

FRENCH, J.D. The reticular formation. Handbook of physiology, Section 1: Neurophysiology Vol. II, 1281-1305, 1960.

Fuster, J.M. And Docter, R.F. Variations of optic evoked potentials as a function of reticular activity in rabbits with chronically implanted electrodes. J. Neurophysiol., 25 : 324-336, 1962.

Gangloff, H. AND Monnier, M. Electrographic aspects of an "arousal" or "attention" reaction induced in the unanesthetized rabbit by the presence of a human being. Electroenceph. clin. Neurophysiol., 8 : 623-629, 1956.

Gastaut, H. et Y., Roger, A., Corriol, J. And Naquet, R. Etude electrographique du cycle d'excitabilité cortical. Electroenceph. clin. Neurophysiol., $3: 401-428,1951$.

Gillilan, L. A. The connections of the basal optic root (posterior accessory optic tract) and its nucleus in various mammals. J. Comp. Neurol., 74: 367-408, 1941.

Green, J. D. And Arduini, A. A. Hippocampal electrical activity in arousal. J. Neurophysiol., $17:$ 533-557, 1954.

Gudden, B. Von. Über den Tractus peduncularis transversus. Arch. Psychiat., 11: 415-423, 1881.

HANBERY, J. W. AND JASPER, H. H. Independence of diffuse thalamocortical projection system shown by specific nuclear distributions. J. Neurophysiol., $16: 252-271,1953$.

Hirota, N. On the flash light response activities in the visual cortex of unanesthetized cats. Acta med. nagasaki., 9: 186-199, 1964.

Hughes, J.R. Responses from the visual cortex of unanesthetized monkeys. Inter- 
national review of neurobiology. 7: 99-152, 1964.

IwASE, Y., UCHIDA, Y. AND Horiuchi, K. The effect of metoclopramide upon the average evoked responses to light stimuli in rabbits and in men. J. Physiol. Soc. Japan. 27 : 514-519, 1965 (in Japanese).

Jasper, H. H. And Ajmone Marsan, C. Thalamocortical integrating mechanisms. Res. Publ. Ass. nerv. ment. Dis., 30: 493-512, 1952.

Klee, M. R. And Offenloch, K. Postsynaptic potentials and spike patterns during augmenting responses in cat's motor cortex. Science. $143: 488-489,1964$.

Klüver, H. ANd BARRERA, E. A method for the combined staining of cells and fibers in the nervous system. J. Neuropath. Exp. Neurol., 12: 400-403, 1953.

Landau, W. M., Bishop, G.H. And Clare, M.H. The interactions of several varieties of evoked response in visual and association cortex of the cat. Electroenceph. clin. Neurophysiol., 13: 43-53, 1961.

MALis, L. I. AND KRUGER, L. Multiple response and excitability of cat's visual cortex. J. Neurophysiol., 19: 172-186, 1956.

Mayer, C. And StrimpF, C. Die Physostigminwirkung auf die Hippocampus-Tätigkeit nach Septumläsionen. Naunyn-Schmiedeberg's Arch.exp. Path. Pharmak., 234 : 490$500,1958$.

Mimura, K. And Sato, K. On the frequency responses of retina and cortex in the rabbit. Jap. J. Physiol., 15: 478-491, 1965.

Mimura, K., Sato, K. And Tomonaga, K. The specific and non-specific components in the cortical potential evoked by sensory stimulation and its relationship with the origin of spontaneous EEG. XXIIIth Int. Congr. Physiol. Sci., 1062, 1965.

Mimura, K., Sato, K., Kitajima, H., Ochi, N. and Ishino, T. Photically evoked potentials in the visnal cortex of rabbits in relation to various electroencephalographic stages. Brain Research, 5 : 306-318, 1967a.

Mimura, K., Sato, K., Kitajima, H. and Ochi, N. Relationship between evoked masspotential and electrical background activity. Jap. J. Physiol., 1967b (in press).

Monnier, M. And Gangloff, H. Rabbit brain research Vol. 1. Elsevier Publishing Co. 1961, Amsterdam.

Moruzzi, G. And Magioen, H. W. Brain stem reticular formation and activation of the EEG. Electroenceph. clin. Neurophysiol., 1: 455-473, 1949.

Narikashilili, S. P. And Moniava, E.S. On the interaction between the thalamocortical projection systems. Pavlov J. higher nerv. Activ. (Moscow), 9: 461-470, 1959.

Parma, M. And Zanchetti, A. Cortical interference between augmenting and recruiting potentials. Proc. XXth int. Physiol., Congr. (Brussels), 703-704, 1956.

Pearlman, A. L. Evoked potentials of rabbit visual cortex: Relationship between a slow negative potential and excitability cycle. Electroenceph. clin. Neurophysiol., 15: 426-434, 1963.

SAто, K. On the linear model of the brain activity in electroencephalographic potential. Folia Psychiat. Neurol. Jap., $17:$ 157-166, 1963.

Sato, K., Honda, N., Mimura, K., Ozaki, T., Teramoto, S. and Kitajima, K. A simplified method for determining the average response time-pattern of the evoked potential in electroencephalography. Electroenceph. clin. Neurophysiol., 14 : 764-766, 1962.

Sato, K., Ozaki, T., Mimura, K., Masuya, S., Honda, N., Nishikawa, T. and Sonoda, $\mathrm{T}$. On the physiological significance of the average time- and frequency-patterns of the electroencephalogram. Electroenceph.clin. Neurophysiol., 13:208-215, 1961.

Sawyer, C. G., EveretT, J. W. And Green, J. D. The rabbit diencephalon in stereotaxic coordinates. J. Comp. Neurol., 141: 801-824, 1954. 
Starzl, T.E. And Magoun, H.W. Organization of the diffuse thalamic projection system. J Neurophysiol., 14 : 133-146, 1951.

STEINBERG, R.H. Alternations of averaged photic evoked potentials in cat visual cortex during repetitive stimulation. Electroenceph. clin. Neurophysiol., 18: 378391, 1965. 